\title{
Influence of Multiple Linear Infrastructure on Diversity of Small Mammals in Mikumi National Park, Tanzania
}

\author{
Agnes Carol Kisanga ${ }^{1}$, Julius WilliamNyahongo ${ }^{1}$, Wambura M. Mtemi ${ }^{2}$ \& Eivin Røskaft ${ }^{3}$ \\ 1. Department of Conservation Biology, The University of Dodoma (UDOM), P.O Box 338 Dodoma, Tanzania
}

2. Department of Natural Resources Management, Mwalimu Julius K. Nyerere University of Agriculture and Technology (MJNUAT), P.O Box 976 Musoma, Tanzania

3. Department of Biology, Faculty of Natural Sciences, Norwegian University of Science and Technology (NTNU), Realfagbygget, Gløshaugen, Høgskoleringen 5, NO-7491 Trondheim, Norway

Correspondence: Agnes Carol Kisanga, Department of Conservation Biology, The University of Dodoma (UDOM), P.O Box 338 Dodoma, Tanzania. Tel: 255-754-392-627, E-mail: carolagnes2011@gmail.com

Received: May 20, 2019

doi:10.5539/enrr.v9n3p41
Accepted: June 5, 2019

Online Published: June 29, 2019

\begin{abstract}
The need for rapid development in developing countries has led to establishment of major public infrastructure even in biodiversity rich protected areas. Mikumi National Park in central Tanzania is traversed by five such major infrastructures namely an optic fibre, a busy public road, an oil pipeline, power lines and railways. We assessed diversity and abundance of small terrestrial mammals of the order Eulipotyphla and Rodentia as indicator groups in relation to impacts of such infrastructure. Animals were live trapped during wet (February-April) and dry (JulySeptember) seasons in 2018 from three established plots along the three transects set perpendicular to each of the four infrastructures. In 10102 trap nights, we captured 453 small mammals of nine species of which Mastomys natalensis constituted $75.4 \%$ of total catch. Diversity and abundance varied between seasons, infrastructure and plots location. Dry season had significantly higher diversity than wet season and the railway site had higher diversity than the other infrastructure. The intermediate plots ( $500 \mathrm{~m}$ from infrastructure) had significantly higher abundance of animals than immediate $(0-50 \mathrm{~m})$ and distant $(1000 \mathrm{~m})$ plots. The differences in these results can be attributed by seasonal fluctuations of animal populations, and intensity of disturbance in each infrastructure and plot. It is important to examine impacts of future infrastructure developments using small mammals.
\end{abstract}

Keywords: Abundance, Diversity, Infrastructure, Mikumi national park, Small mammals

\section{Introduction}

Infrastructure development is one of the factors affecting biodiversity in various parts of the world. In developing countries, the need for rapid development has led to establishment of public major infrastructure such as roads, railways, oil pipelines and power lines even in biodiversity rich protected areas (Costantinos, 2011). In Tanzania for example, a number of infrastructures have been established in protected areas such as public roads along the Ngorongoro Conservation Area, as well as Katavi, Serengeti, and Mikumi National Parks. In some cases like Mikumi National Park which is the focus of this study, there are five types of major infrastructures; namely an optic fibre, a public road, an oil pipeline, overhead power lines and railways. Some infrastructures were established prior to the establishment of Enviromental Impact Assessment (EIA) regulations in the country. Sometimes, due to political motives and the economic urgency need of such infrastructure, some were established without conducting proper EIAs (Guilanpour \& Sheate, 1997). Thus, failure of conducting an EIA might have led to paucity of baseline data which would be available for evaluation of short- and long-term effects of such infrastructure to the environment and particularly to wildlife, after their establishment.

There is a number of recent literature reporting the effects of these infrastructure on wildlife. Trombulak and Frissell (2000) in their review concluded a high correlation between presence of roads with changes in species composition and population size. Coffin (2007) also gave an overview of ecological effects of roads including noise and other atmospheric pollution, barrier for animal movement and road mortalities, roads as habitats, corridors and conduit for wildlife and finally development of road ecology as a body of scientific enquiry. On the other hand, Laurance, Goosem and Laurance (2009) report effects of roads being more prominent in tropical 
rainforests than other ecosystems due to their complexity. The effects of railways on wildlife are more or less similar to those of roads as reported in Dorsey, Olsson and Rew (2015) and Popp and Boyle (2017). However, some cases and magnitudes of impact differ from roads for instance electrocution, rail entrapments and wire strikes, therefore demand different mitigation measures. The power lines pose additional effects of electromagnetic fields which cause avoidance by some animals (Bartzke et al., 2014) . Oil spills from pipelines add to the effects, despite being rare they can be very devastating on environment and last for longer time (Richardson et al., 2017). Most of the available studies are not only based in Europe and America (Benítez-López, Alkemade \& Verweij 2010; Richardson et al., 2017), but they are also largely focused on large animals in relation to separate infrastructure types. This focus may not always be considered as effective representative of small mammals (Caro, 2001) especially from tropical savannahs.

The nature of small mammals such as their relatively small size, high reproductive capacity, rapid invasion, easy to capture and identify, has made them useful ecological indicators (Merrit 2010). Through their presence, absence, diversity and abundance they can indicate various forms of ecological disturbances such as fire (Converse et al., 2006), grazing (Mugatha, 2002) and deforestation (Kirkland, 1990) but also ecosystem succession and integrity (Ecke, 2002; Sullivan, Lautenschlager \& Wagner, 1999). In this paper, we report diversity and abundance of small mammals as indicators for disturbance of four linear infrastructures in Mikumi National Park, Eastern Tanzania. We hypothesize that, the diversity and abundance of small mammals will increase along a gradient of distance away from the four infrastructures.

\section{Materials and Methods}

\subsection{Study area}

The Mikumi National Park is located in eastern Tanzania between $7^{\circ} 00^{\prime}$ and $7^{\circ} 50^{\prime} \mathrm{S}$ and between $37^{\circ} 00^{\prime}$ and $37^{\circ} 30^{\prime} \mathrm{E}$. It is the fifth largest national park in Tanzania established as a Game Reserve in 1954 and later upgraded to a national park in 1964, covering $3,230 \mathrm{~km}^{2}$ (TANAPA, 2013). The park is surrounded by settlements except in the south where it borders Africa's largest game reserve and a World Heritage Site, the Selous. The altitude of the park ranges from $230 \mathrm{~m}$ on the Mkata Flood Plain, to $1,270 \mathrm{~m}$ at the Malundwe Mountains, which are part of the Eastern Arc Mountains. This altitudinal range gives the park heterogeneous habitats ranging from grassland to mixed woodland mosaics, that support a rich diversity of flora and fauna. The park harbours about 1,600 species of plants and over 60 mammal species. It is also home for around 500 avifauna both resident and migratory (TANAPA, 2017). Mikumi National Park is uniquely transversed by five linear infrastructures. First the TANZAM highway, which connect Tanzania and Zambia, crosses the park at a stretch of about $50 \mathrm{~km}$. Second, parallel to TANZAM is Tanzania Zambia Mafuta (TAZAMA) pipeline, commissioned in 1968 with a diameter of 8-12 inches crossing the park with almost a similar stretch and recently an optic fibre introduced in 2016. In addition, the park is traversed by two railways; the abandoned Tanzania Railway Corporation (TRC) (commissioned in 1977) and Tanzania Zambia Railway Authority (TAZARA) (commissioned 1975). Finally, two high tension power lines (commissioned between 1979-1984) from lower Kihansi and Kidatu power stations traverse the park (Figure 1).

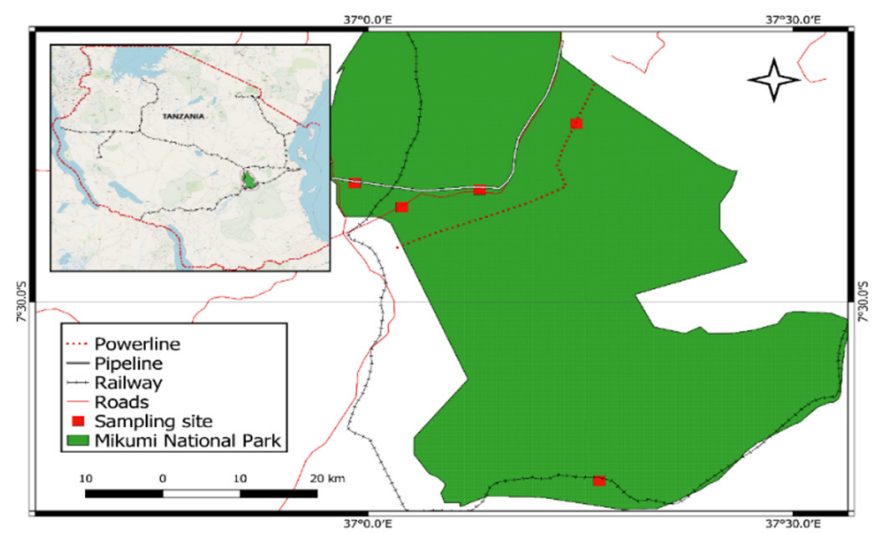

Figure 1. Map of Mikumi National Park (MINAPA) showing public major infrastructures traversing the Park

\subsection{Small Mammals Sampling}

Small mammals were trapped during both wet (February to April) and dry (July to September) seasons in 2018 from three established plots along the three transect lines set perpendicular to each infrastructure. A preliminary 
survey was conducted to establish suitable areas for establishing the transects. Areas with similar topography was considered suitable in order to avoid topographical variations, which also determines differences in both plants and animal diversity (McCain, 2005; Wikum \& Wali, 1974). The immediate plot in each transect was set immediately after the right of way (ROW) margin of each infrastructure, the intermediate and distant plots were set at $500 \mathrm{~m}$ and $1000 \mathrm{~m}$ respectively.

The transects were set $2 \mathrm{~km}$ apart and the plot had $100 \mathrm{~m}$ x $100 \mathrm{~m}$ size with two trap lines spaced at $50 \mathrm{~m}$. The trap lines had 10 Shermans live traps $(230$ x 95 x80 mm, H. B. Sherman's Traps, Inc., Tallahassee, FL, U.S.A.) placed $10 \mathrm{~m}$ apart, and baited with fried sardines and peanuts (Figure 2). For places where two infrastructure overlap, for example the road and pipeline, additional sampling was conducted to determine whether the combination of the two had different effects to small mammal community.

In principle target animals were small terrestrial mammals of the order Eulipotyphla and Rodentia. Traps were checked and re-baited (when necessary) once a day from 07:00 hrs. for six consecutive days. Checking of traps was confined in mornings only after preliminary surveys, resulting in insignificant captures in the afternoons. Captured animals were identified by aid of a field guide (Kingdon, 1997), marked by shaving on the underside of the animal in a specific pattern and released at the point of capture in order to score recaptures. For animals which were not able to identify immediately pictures were taken for further identification later.

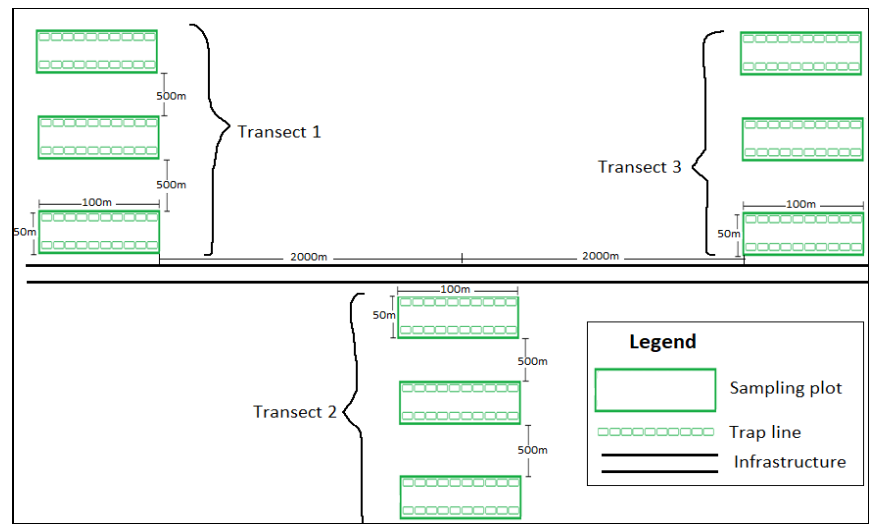

Figure 2. A sketch of small mammals sampling layout

\subsection{Data Analysis}

For easy analysis understanding of the data the infrastructure was coded as RD $=$ highway, $\mathrm{PP}=$ pipeline, $\mathrm{RP}=$ combination of highway and pipeline, $\mathrm{PW}=$ power line and $\mathrm{RL}=$ railway. Statistical comparisons of Shannon-diversity was computed and compared between plots and seasons by diversity t-tests (Hutcheson, 1970) in PAST software (Hammer, Ryan, \& Hammer, 2001). Due to insufficient captures, animals were grouped into three groups namely, Mastomys natalensis, Crocidura species and others which includes all the other species. These groups were specifically used for assessment of trap success. Trap success for each day in each plot was obtained by dividing total number of trapped individuals to the total of trapping effort times hundred trap nights. Due to high number of zeroes which lead to over dispersion of data, Zero Inflated Poisson (ZIP) (Zuur, Walker, Saveliev, \& Smith, 2009) was employed to model the influence of species, season, infrastructure and plot distance on trap success. Graphs for trapping success were plotted in R software while results was considered as statistically significant at $95 \%$ Confidence Interval $(\mathrm{p}<0.05)$.

\section{Results}

During a total of 10102 trap nights 453 individuals (plus 41 recaptures) were recorded of which 148 and 305 individuals were trapped in wet and dry season sessions, respectively. The animals belong to three orders (Carnivora, Eulipotyphla and Rodentia), of which four species (Mastomys natalensis, Lemniscomys rosalia, Acomys wilsoni and Crocidura spp) were captured in the wet season. In the dry season additional five species (Gerbilus spp, Aethomys spp, Dasymys incomtus, Arvicanthis spp and a baby mangoose Herpestes sanguineus) together with those captured in the wet season were captured, making a total of nine species during the whole study. The most abundant species was Mastomys natalenis followed by Crocidura spp (Table 1). 
Table 1. The percent captures of small mammals' species at Mikumi National Park (2018)

\begin{tabular}{lll}
\hline Species & Wet season $(\mathrm{n}=148)$ & Dry season $(\mathrm{n}=305)$ \\
\hline Mastomys natalensis & 79.7 & 71.1 \\
Crocidura spp & 16.2 & 13.1 \\
Lemniscomys rosalia & 1.3 & 5.2 \\
Gerbilus spp & 0 & 6.9 \\
Acomys wilsoni & 2.7 & 1.6 \\
Aethomys spp & 0 & 0.7 \\
Dasymys incomtus & 0 & 0.3 \\
Arvicanthis spp & 0 & 0.3 \\
Herpestes sanguineus & 0 & 0.7 \\
Total & 100 & 100 \\
\hline
\end{tabular}

\subsection{Small Mammal Diversity}

In general Shannon diversity was marginally higher $(\mathrm{p}<0.01$, $\mathrm{df}=373)$ during the dry $(H=1.03)$ than wet season $(H=0.63)$. Pairwise comparison of plots indicated a significant higher diversity of small mammals in the immediate than distant plots $(\mathrm{t}=-2.14, \mathrm{df}=64, \mathrm{p}=0.036)$ during the wet season but no significant variation was observed during the dry season. Comparisons of diversities between plots across infrastructure and seasons is shown in Table 2.

Table 2. Pairwise comparison of Shannon diversity between infrastructure and seasons within similar plots. Only significant values $(\mathrm{p}<0.05)$, their respective degrees of freedom $(\mathrm{df})$ and t-values by diversity t-test are given.

\begin{tabular}{|c|c|c|c|c|c|c|c|c|c|}
\hline Season & Immediate & (df) $\mathrm{T}$ & $\mathrm{P} \leq$ & Intermediate & (df) $\mathrm{T}$ & $\mathrm{P} \leq$ & Distant & (df) $\mathrm{T}$ & $\mathrm{P} \leq$ \\
\hline \multirow[t]{2}{*}{ Wet } & PW- RD & (21) 3.0 & 0.002 & RD-RP & 17.0 & 0.0001 & $\mathrm{~ns}$ & - & - \\
\hline & PW- PP & (11) 2.3 & 0.042 & & & & $\mathrm{~ns}$ & - & - \\
\hline \multirow[t]{4}{*}{ Dry } & RD-RL & (15) -3.5 & 0.003 & RD- PW & (23) -4.1 & 0.0004 & RD-RL & (17) 3.2 & 0.004 \\
\hline & PP-RL & (38) -2.4 & 0.01 & PP -PW & (32) -8.1 & 0.0001 & PP-RL & (19) 3.5 & 0.002 \\
\hline & RP-RL & (37) -3.3 & 0.0017 & RP- PW & (37) -8.0 & 0.0001 & RP-RL & (23) 2.3 & 0.03 \\
\hline & PW-RL & $(45)-2.3$ & 0.02 & & & & PW-RL & (17) 3.1 & 0.006 \\
\hline
\end{tabular}

$\mathrm{RD}=$ Highway, $\mathrm{PP}=$ Pipeline, $\mathrm{RP}=$ Highway and pipeline, $\mathrm{PW}=$ Powerline, $\mathrm{RL}=$ Railway $\mathrm{ns}=$ not significant.

\subsection{Trap Success of Small Mammals}
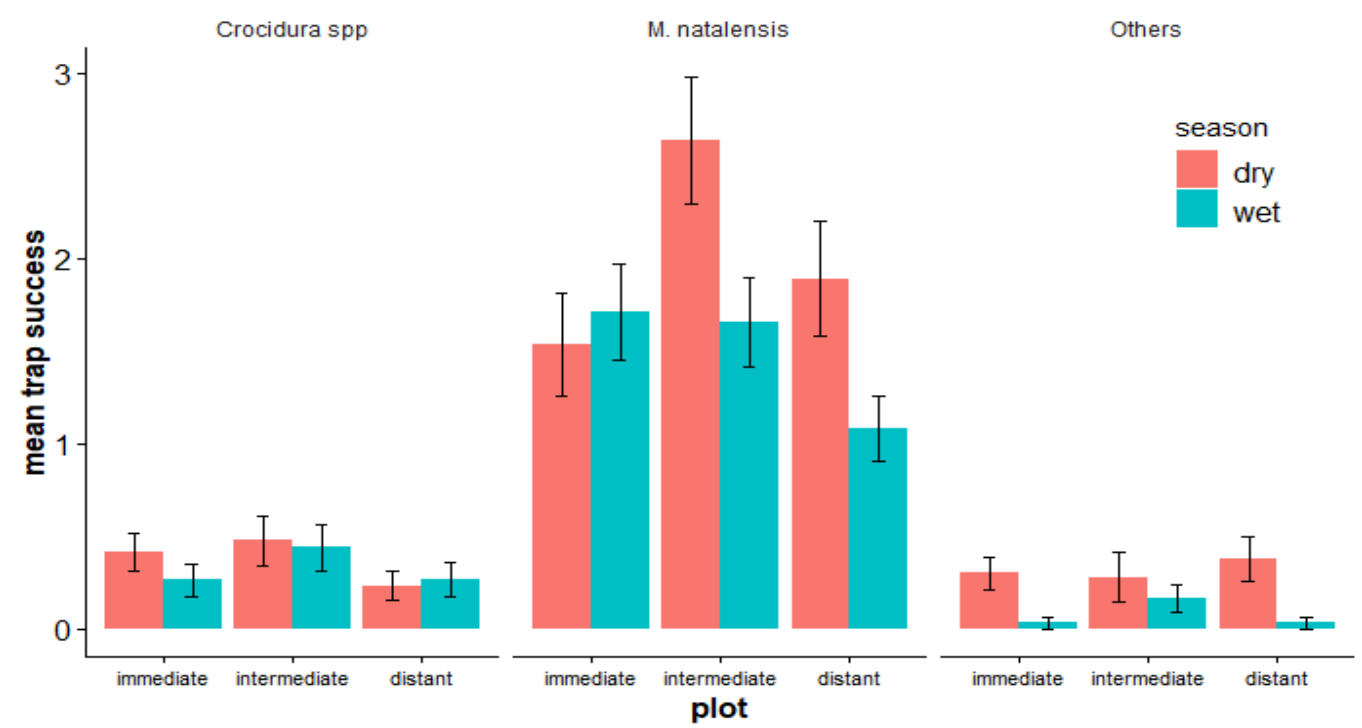

Figure 3. Trap success (mean $\pm \mathrm{SE}$ ) of small mammals along the gradient of distance from infrastructure in Mikumi National Park (2018) during dry and wet seasons 
Overall trap success was higher during the dry season than the wet season. The power line and pipeline sites had relatively higher number of catches compared to the railway, road and combination of road and pipeline (Table 3). Crocidura spp had similar trapping success during both seasons but M. natalensis and others had significantly higher trapping success during the dry season. Additionally, there were higher catches of Crocidura spp and others in the intermediate plots in both seasons. M. natalensis had more or less similar trap success in all plots in wet season while slightly higher trap success in the intermediate plots during the dry season. (Figure 3).

Table 3. Summary of statistical analyses of the influence of species, season, infrastructure and plot distance on trap success. Wet season was compared with dry season, all infrastructure was compared with pipeline, other plots were compared with distant plots, M. natalensis and other species were compared with Crocidura species

\begin{tabular}{lrrrr}
\hline Covariate & Estimate & $\mathrm{SE}$ & $\mathrm{z}$ & $\mathrm{P} \leq$ \\
\hline Intercept & 1.953 & 0.078 & 24.797 & 0.001 \\
Species M. natalensis & 0.425 & 0.059 & 7.106 & 0.001 \\
Species other & 0.068 & 0.100 & 0.678 & 0.497 \\
Season wet & -0.402 & 0.047 & -8.548 & 0.001 \\
Infrastructure PW & 0.008 & 0.064 & 0.134 & 0.893 \\
Infrastructure RD & -0.106 & 0.064 & -1.654 & 0.098 \\
Infrastructure RL & -0.489 & 0.139 & -3.502 & 0.014 \\
Infrastructure RP & -0.113 & 0.066 & -1.720 & 0.085 \\
Plot intermediate & 0.121 & 0.054 & 2.242 & 0.024 \\
Plot immediate & 0.043 & 0.057 & 0.749 & 0.453 \\
\hline Intercept & 2.329 & 0.255 & 9.136 & 0.001 \\
Species M. natalensis & -1.611 & 0.167 & -9.622 & 0.001 \\
Species other & 0.701 & 0.219 & 3.190 & 0.001 \\
Season wet & 0.053 & 0.160 & 0.330 & 0.741 \\
Infrastructure PW & -0.377 & 0.237 & -1.587 & 0.112 \\
Infrastructure RD & -0.599 & 0.223 & -2.683 & 0.007 \\
Infrastructure RL & 1.217 & 0.388 & 3.136 & 0.001 \\
Infrastructure RP & -0.342 & 0.236 & -1.447 & 0.147 \\
Plot immediate & -0.103 & 0.194 & -0.533 & 0.593 \\
Plot intermediate & -0.400 & 0.191 & -2.088 & 0.036 \\
\hline
\end{tabular}

\section{Discussion}

\subsection{Diversity of Small Mammals}

Our results show that the diversity of small mammals vary relatively between seasons and distance from the studied infrastructure. The slightly high diversity in the dry season could be attributed by high abundance and activity of individuals of some species on the onset the season which increase trappability rate. Martin (1985) reports similar observation where population of small rodents in tropical sub humid grasslands increased after the rain season. The railway site had highest Shannon diversity $\left(H^{\prime}=1.65\right)$ of small mammals compared to other infrastructure. The difference in diversity could be attributed by differences in vegetation cover. The railway is situated in the southern part of the park which is predominantly covered by the miombo woodlands while the rest of other infrastructure located in the northern part of the park covered by wooded grassland (Mogba 2006). Elsewhere it is reported that there is relative high diversity of rodents in areas with relative dense vegetation cover than open grassland (Magige, 2013; Saetnan \& Skarpe, 2008).

The immediate plots especially along road and pipeline had relative high diversity than the further plots during the wet season. This tendency could be explained by two reasons namely, there is scarcity of forage during onset of wet season therefore animals are likely to shift towards the road pipeline where there is readily available food staffs from passenger littering from vehicles along the highway and surveillance personnel along the pipeline. Also in the beginning of raining the greening begin earlier on road edges due to surface runoff therefore attract foraging animals. Nyahinga, Ringo, Mashalla, and Mayengo (2016) reported high degree of littering along the Mikumi highway, but also Drews (1995) reported attraction of some baboons towards the same highway.

Our study report lower diversity of small mammals compared to previous studies in Mikumi National Park (Venance, 2009). This was expected due to the nature of our study which required sites from all infrastructure been as homogenous as possible so as to avoid topographical and vegetation variations. It is worth noting that, in 
this study five species namely M. natalensis, L. rosalia D. incomtus, Aethomys spp and Arvicanthis spp are recorded for the first time in this park. D. incomtus was recorded only along the road and Aethomys spp and Arvicanthis spp were recored along the railway while M. natalensis and L. rosalia were recorded in all infrastructure. These species are widely documented in other parts of Tanzania as agriculture and household pests. (Caro, 2001; Makundi et al., 1991; Mulungu et al., 2015).

\subsection{Trap Success of Small Mammals}

High trap success in dry season could be attributed by high abundance of small mammals in the the season due to availability of cover and food which is plenty soon after the rainy season. Similar seasonal variations on small mammals abundance are reported by Caro (2001) in Katavi National Park Tanzania and Tilahun, Defar and Habte (2017) in Chebera Churchura National Park Ethiopia.

There were overall low catches along the highway, railway and combination of highway and pipeline. They could be attributed by the high frequency of human interference compared to power lines and pipeline sites. The frequent use by vehicles and trains, which require frequent mowing increase rates of human disturbance, as opposed to the power lines and pipeline where human movements are less frequent (Park ecologist, personal communication August 29, 2017). The high impact and activity by humans are probably the cause of avoidance by the small mammals (Peter et al., 2013).

The results also show a significantly higher overall trap success in the intermediate plots. This tendency could be explained by the Intermediate Disturbance Hypothesis (IDH) given by (Connell, 1978). Small mammals prefer moderately disturbed habitats, the intermediate plots in this study are considered moderately disturbed compared to immediate which is considered highly disturbed and distant plots which is considered less disturbed. Mastomys natalensis on the other hand slightly deviated from IDH by having marginally high abundance in the immediate plots during the wet season. This could be due the generalist nature of $M$. natalensis which permit them persist in almost all habitats including the edge habitats. The species being synanthropic, could be moving towards the infrastructure edges to forage on cheaply available litter thrown by passenger along the infrastructure.

\section{Conclusions and Recommendations}

Infrastructure influences small mammal diversity and abundance within protected areas in various ways. Thus, an intermediate level of disturbance is desirable for increased abundance of small mammals. Further, seasonality influences both diversity and abundance along infrastructure such that it was higher in dry than wet periods. In addition, human disturbance vary between infrastructure and therefore call for different mitigation measures. Based on these findings we recommend infrastructure in protected areas to be well planned to avoid negative impacts on biodiversity by reducing fragmentation of habitats. We also recommend increased conservation education and law enforcement within protected areas to the public to reduce unnecessary littering in PAs. Enhanced wildlife management requires detailed periodic surveys of small animals in the park for updated biodiversity records and information.

\section{Acknowledgements}

We would like to thank the PELIBIGO project under Energy and Petroleum (EnPe) supported by NORAD for their financial support. We also appreciate Omari Ally of SUA Pest Management Center for his assistance in the field and the Management of Mikumi National Park for providing us with all the field support we required.

\section{Conflict of interests}

The authors declare that there is no conflict of interests regarding the publication of this paper.

\section{References}

Bartzke, G. S., May, R., Bevanger, K., Stokke, S., \& Røskaft, E. (2014). The effects of power lines on ungulates and implications for power line routing and rights-of-way management. International Journal of Biodiversity and Conservation. 6(9), 647-662. https://doi.org/10.5897/IJBC2014.0716

Benítez-López, A., Alkemade, R., Verweij P. A. (2010).The impacts of roads and other infrastructure on mammal and bird populations:A meta-analysis. Biological Conservation, 143, 1307-1316

Caro, T. M. (2001). Species richness and abundance of small mammals inside and outside an African national park. Biological Conservation. 98, 251-257. https://doi.org/10.1016/S0006-3207(00)00105-1

Coffin, A. W. (2007). From roadkill to road ecology: A review of the ecological effects of roads. Journal of Transport Geography, 15(5), 396-406. https://doi.org/10.1016/j.jtrangeo.2006.11.006

Connell, J. H. (1978). Diversity in Tropical Rain Forests and Coral Reefs. Science, 199, 1302-1310. 
https://doi.org/10.1126/science.199.4335.1302

Converse, S. J., White, G. C., Farris, K. L., \& Zack, S. (2006). Small mammals and forest fuel reduction: National-scale responses to fire and fire surrogates. Ecological Applications, 16(5), 1717-1729. https://doi.org/10.1890/1051-0761(2006)016[1717:SMAFFR]2.0.CO;2

Costantinos, C. B. (2011). Programme for Infrastructure Development in Africa - PIDA Creating Jobs for Africa's Youth. Retrieved from http://www.academia.edu/18966156/Programme_for_Infrastructure_Development_in_Africa_-_PIDA_Creati ng_Jobs_for_Africa_s_Youth

Dorsey, B., Olsson, M., \& Rew, L. (2015). Ecological Effects of Railways on Wildlife. In R. van de Ree, D. J. Smith, \& C. Grilo (Eds.), Handbook of Road Ecology (pp. 219-227). https://doi.org/10.1002/9781118568170.ch26

Drews, C. (1995). Road kills of animals by public traffic in Mikumi National Park, Tanzania, with notes on baboon mortality. African Journal of Ecology, 33(2), 89-100. https://doi.org/10.1111/j.1365-2028.1995.tb00785.x

Ecke, F., Löfgren O., \& Sörlin, D. (2002). Population dynamics of small mammals in relation to forest age and structural habitat factors in northern Sweden. Journal of Applied Ecology, 39(5), 781-792. https://doi.org/10.1046/j.1365-2664.2002.00759.x

Guilanpour K., \& Sheate W. R. (1997). A systematic review of Tanzanian environmental impact statements. Project Appraisal, 12(3), 138-150. https://doi.org/10.1080/02688867.1997.9727053

Hammer, D. A. T., Ryan, P. D., \& Hammer, Ø. (2001). Past: Paleontological Statistics Software Package for Education and Data Analysis. Palaeontologia Electronica, 4(1), 178.

Hutcheson, K. (1970). A test for comparing diversities based on the shannon formula. Journal of Theoretical Biology, 29(1), 151-154. https://doi.org/10.1016/0022-5193(70)90124-4

Kingdon, J. (1997). The Kingdon field guide to African mammals. San Diego: AP Natural World Academic Press, Harcourt Brace \& Company.

Kirkland, G. L. (1990). Patterns of initial small mammal community change after clearcutting of temperate North American forests. Oikos, 59(3), 313-320. https://doi.org/10.2307/3545141

Laurance, W. F., Goosem, M., \& Laurance, S. G. W. (2009). Impacts of roads and linear clearings on tropical forests. Trends in Ecology \& Evolution, 24 (12), 659-669. https://doi.org/10.1016/j.tree.2009.06.009

Lucas, P. S., de Carvalho, R. G., \& Grilo, C. (2017). Railway Disturbances on Wildlife: Types, Effects, and Mitigation Measures. Railway Ecology (pp. 81-99). https://doi.org/10.1007/978-3-319-57496-7_6

Magige, F. J. (2013). Rodent species diversity in relation to altitudinal gradient in Northern Serengeti, Tanzania. African Journal of Ecology, 51(4), 618-624. https://doi.org/10.1111/aje.12075

Makundi, R., Kilonzo, B., Undi, R. H. M., Mbise, T. J., \& Kilonzo, B. S. (1991). Observations on the role of rodents in crop losses in Tanzania and control strategies. Beitr. Trop. Landwirtsch. Vet.Med., 29(4), $465-474$. https://www.researchgate.net/publication/290159417

Martin G. H. G. (1985). A population study of small rodents in a dry sub-humid grassland in Kenya . Journal of Tropical Ecology 1,217-224

McCain, C. M. (2005). Elevational Gradients in Diversity of Small Mammals. Ecology, 86(2), 366-372. https://doi.org/10.2307/3450957

Merrit, J. F. (2010). The Biology of Small Mammals. Baltimore, Meryland: The John Hopkins University Press.

Mogba, G. (2006). Structural, Floristic Composition and Diversity of Vegetation Communities in Mikumi National Park. (Master's thesis Addis Ababa University Ethiopia). Retrieved from http://etd.aau.edu.et/bitstream/handle/123456789/9293/Neema Mogha.pdfsequence=1\&isAllowed=y

Mugatha, S. M., (2002). Influence of Land Use Patterns on Diversity, Distribution and Abundance of Small Mammals in Gachoka Division, Mbeere District, Kenya . Working Paper Number: 8. CGSpace A Repository of Agricultural Research Outputs Retrieved from https://cgspace.cgiar.org/handle/10568/1876

Mulungu, L. S., Sixbert, V., Ngowo, V., Mdangi, M., Katakweba, A. S., Tesha, P., ... Belmain, S. R. (2015). Spatio-temporal patterns in the distribution of the multi-mammate mouse, Mastomys natalensis, in rice crop and fallow land habitats in Tanzania. Mammalia, 79(2), 177-184. https://doi.org/10.1515/mammalia-2014-0006

Nyahinga, T., Ringo, J., Mashalla, A., \& Mayengo, G. (2016). Quantification of Solid Wastes along the Highway Crossing Mikumi National Park, Tanzania. International Journal of Modern Social Sciences, 5(52), 140-152. http://modernscientificpress.com/Journals/ViewArticle.aspx

Peter, F. P., Molina-Vacas, G., Rodriguez, J., \& Grilo, C. (2013). Effects of roads on spatial behaviour and abundance of small mammals: gaps in knowledge. Oecologia Australis, 17(1), 63-76. 
https://doi.org/10.4257/oeco.2013.1701.06

Popp, J. N., \& Boyle, S. P. (2017). Railway ecology: Underrepresented in science? Basic and Applied Ecology, 19, 84-93. https://doi.org/10.1016/j.baae.2016.11.006

Richardson, M. L., Wilson, B. A., Aiuto, D. A. S., Crosby, J. E., Alonso, A., Dallmeier, F. \& Golinski, G. K. (2017). A review of the impact of pipelines and power lines on biodiversity and strategies for mitigation.

Biodiversity and Conservation, 26(8), 1801-1815. https://doi.org/10.1007/s10531-017-1341-9

Saetnan, E. R., \& Skarpe, C. (2008). The effect of ungulate grazing on a small mammal community in southeastern Botswana. African Zoology, 41(1), 9-16. https://doi.org/10.3377/1562-7020(2006)41[9:teougo]2.0.co;2

Sullivan, T. P., Lautenschlager, R. A., \& Wagner, R. G. (1999). Clearcutting and burning of northern spruce-fir forests: implications for small mammal communities. Journal of Applied Ecology, 36(3), 327-44. https://doi.org/10.1046/j.1365-2664.1999.00408.x

TANAPA. (2013). TANAPA Today. Tanzania National Parks, 15, 1-36. Retrieved from https://www.bookletia.com/api/ebooks/968/pdf/Tanapa\%20Today\%20No.14.pdf?download

TANAPA. (2017). Tanzania National Parks - Mikumi National Park. Retrieved from http://www.tanzaniaparks.go.tz/index.php?option=com_content\&view=article\&id=36:mikumi-national-park \&catid $=8$ \&Itemid $=112$

Tilahun, D. H., Defar, B. D., \& Habte, G. G. (2017). Species abundance, structure and seasonal variation of small mammals in the CCNP. African Journal of Ecology and Ecosystems, 4(1), 234-241. www.internationalscholarsjournals.org

Trombulak, S. C., \& Frissell, C. A. (2000). Review of Ecological Effects of Roads on Terrestrial and Aquatic Communities. Conservation Biology, 14(1), 18-30. https://doi.org/10.1046/j.1523-1739.2000.99084.X

Venance, J. (2009). Small mammal communities in the Mikumi National Park, Tanzania. Hystrix It. J. Mamm, 20(2), 91-100. http://www.italian-journal-of-mammalogy.it/article/viewFile/4439/4375

Wikum, D. A., \& Wali, M. K. (1974). Analysis of a North Dakota Gallery Forest: Vegetation in Relation to Topographic and Soil Gradients. Ecological Monographs, 44(4), 441-464. https://doi.org/10.2307/1942449

Zuur, A. F., Ieno, E. N., Walker, N., Saveliev, A. A., \& Smith, G. M. (2009). Mixed effects models and extensions in ecology with $R$. https://doi.org/10.1007/978-0-387-87458-6

\section{Copyrights}

Copyright for this article is retained by the author(s), with first publication rights granted to the journal.

This is an open-access article distributed under the terms and conditions of the Creative Commons Attribution license (http://creativecommons.org/licenses/by/4.0/). 